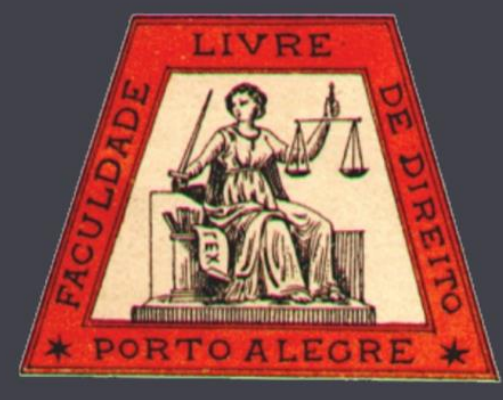

\title{
Precedentes e jurisdição constitucional no Novo Código de Processo Civil
}

\section{Precedents and constitutional jurisdiction in the new Brazilian Code of Civil Procedure}

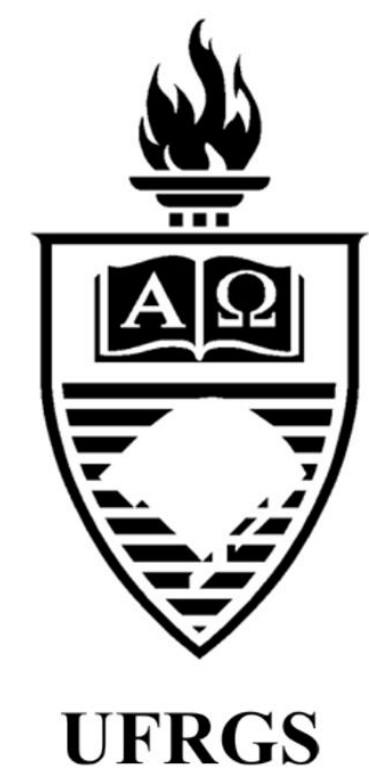

Adriano Gonçalves Feitosa
Universidade Federal do Amazonas

Bernardo Silva de Seixas

Universidade Federal do Amazonas

Jhennifer Cristine Souza Pinto

Universidade Federal do Amazonas 


\title{
Precedentes e jurisdição constitucional no Novo Código de Processo Civil
}

\author{
Precedents and constitutional jurisdiction in the new Brazilian Code of Civil Procedure
}

Adriano Gonçalves Feitosa*

Bernardo Silva de Seixas**

Jhennifer Cristine Souza Pinto***

\section{REFERÊNCIA}

FEITOSA, Adriano Gonçalves; PINTO, Jhennifer Cristine Souza; SEIXAS, Bernardo Silva de. Precedentes e jurisdição constitucional no Novo Código de Processo Civil. Revista da Faculdade de Direito da UFRGS, Porto Alegre, n. 35, p. 233-251, dez. 2016.

\section{RESUMO}

Este trabalho pretende demonstrar a realidade inaugurada pelo NCPC - Novo Código de Processo Civil (CPC/2015) -, apontando-lhe as inovações pertinentes ao exercício jurisdicional, à medida que o novo código, em consonância com o moderno direito processual constitucional, reforça a vinculação de certas decisões e as adequa à teoria dos precedentes judiciais. Paralelamente, é necessário comentar, em linhas gerais e numa perspectiva histórica, a respeito da interação entre os sistemas do Common Law e do Civil Law no sistema brasileiro e sua influência ao longo da trajetória de consolidação da jurisdição constitucional e processual pátria. Afinal, melhor se compreende o NCPC diante das reformas processuais promovidas ainda durante a vigência do CPC/1973. Por fim, evidencia-se o papel do Supremo Tribunal Federal como Corte Constitucional e a motivação que isso representa para a força dos precedentes no $\mathrm{CPC} / 2015$.

\section{PALAVRAS-CHAVE}

Precedentes. Novo Código de Processo Civil. Controle de Constitucionalidade. Supremo Tribunal Federal.

\begin{abstract}
This paper aims to show the news introduced by the new Brazilian Code of Civil Procedure (CPC/2015), pointing out the relevant innovations in the judicial exercise, so far as the legal innovation, in line with the modern constitutional Procedural Law, reinforces the binding quality of certain judicial decisions based on a theory of legal precedents. At the same time, it had to be commented, very briefly and in a historical perspective, on the interaction between the systems of Common Law and Civil Law in the Brazilian legal system and its influence over the consolidation path of constitutional and procedural jurisdiction. After all, the NCPC can be understood through the procedural reforms promoted during the term of the old procedural law (CPC/1973). Finally, this paper highlights the role of the Supreme Court as a Constitutional Court and what this represent for the precedents in the New Brazilian Code of Civil Procedure.
\end{abstract}

\section{KEYWORDS}

Precedents. New Brazilian Code of Civil Procedure. Judicial Review. Brazilian Supreme Federal Court.

\section{SUMÁRIO}

Introdução. 1. Noções gerais. 2. O Estado e a jurisdição constitucional. 3. As reformas processuais. 4. Os precedentes no Novo Código de Processo Civil. 5. Os precedentes e o Supremo Tribunal Federal. 6. Duas novidades do CPC/2015: o Incidente de Resolução de Demandas Repetitivas (IRDR) e o Incidente de Assunção de Competência (IAC). Conclusão. Referências.

\footnotetext{
* Graduando em Direito (Universidade Federal do Amazonas - UFAM).

** Professor da Universidade Federal do Amazonas (UFAM) e do Centro Universitário de Ensino Superior do Amazonas (CIESA). Mestre em Sistema Constitucional de Garantia de Direitos (Instituição Toledo de Ensino - ITE, 2014). Especialista em Direito Processual (Centro Universitário de Ensino Superior do Amazonas - CIESA, 2013). Graduado em Direito (Centro Universitário de Ensino Superior do Amazonas - CIESA, 2011).

*** Graduanda em Direito (Universidade Federal do Amazonas - UFAM).
} 
A Odisseia [de Homero] é a história de um movimento ao mesmo tempo em direção a uma meta e sem meta nenhuma; bem-sucedido e em vão. Em que a História do Direito é diferente disso?

Bernhard Schlink, em O Leitor

\section{INTRODUÇÃO}

O presente trabalho visa a esboçar uma perspectiva atualizada dos precedentes judiciais e da jurisdição constitucional no Novo Código de Processo Civil, materializado na Lei $n^{\circ}$ 13.105/2015 e vigente desde 18 de março de 2016.

Este estudo encontra respaldo em problemáticas ainda atuais, que seguem sendo discutidas pela doutrina e pela jurisprudência superior, quais sejam: a carga de efetividade que ganham os precedentes judiciais a partir da edição do Novo Código de Processo Civil; a medida de aproximação do novo sistema brasileiro com os ordenamentos tradicionalmente filiados ao sistema anglo-saxão, referente ao Common Law; e, ainda, o grau de efetivação que tal comunicabilidade sistêmica implica no desempenho das funções históricas e institucionais do Supremo Tribunal Federal (STF) enquanto Corte Constitucional.

Propõe-se, portanto, a elencar as inovações pertinentes ao exercício da jurisdição constitucional concentrada consoante a teoria dos precedentes judiciais; analisar os precedentes judiciais no âmbito exclusivo do STF; e, por fim, avaliar se a consagração dos precedentes judiciais tal qual vislumbrados no novo diploma processual civil representa inclinação do ordenamento brasileiro ao sistema da Common Law.

Inicialmente, caberá contextualizar a temática pretendida em suas noções gerais. Em seguida, discutir-se-á o Estado e a jurisdição constitucional, traçando brevemente a sua cronologia histórica de consolidação. Logo após, investiga-se de que forma se operaram as reformas processuais civis no ordenamento brasileiro nas últimas décadas e de que forma estas se respaldaram na operacionalização dos direitos fundamentais contidos na Constituição de 1988.

Em sequência, adentra-se propriamente no campo dos precedentes judiciais, analisando-os sob a perspectiva do Novo Código de Processo Civil (Lei $\left.n^{\circ} 13.105 / 2015\right)$. Parte-se, então, para uma análise individualizada dos precedentes na seara de atuação do Supremo Tribunal Federal. Por fim, conclui-se este trabalho com a breve abordagem de duas novidades do CPC/2015, apresentadas em suas linhas gerais: o Incidente de Resolução de Demandas Repetitivas (IRDR) e o Incidente de Assunção de Competência (IAC).

Com o intuito de alcançar satisfatoriamente os fins aqui pretendidos, aplicar-se-á nesta pesquisa o método hipotético-dedutivo, auxiliado pelos métodos histórico e comparativo. Nesse ínterim, para a confirmação das hipóteses ora firmadas, proceder-se-á ao estudo dos dispositivos da Lei $n^{\circ}$ 13.105/2015 (Novo CPC) cuja pertinência temática permita dar ênfase aos aspectos procedimentais dos precedentes judiciais no âmbito do Supremo Tribunal Federal.

\section{NOÇÕES GERAIS}

A cultura jurídica brasileira, apesar de ser popularmente remetida à tradição do Civil Law, vinha reclamando uma prática de maior respeito aos precedentes judiciais, tal qual a observada em países integrantes da Common Law.

Há tempos a doutrina flerta com o tema. Ao longo das duas últimas décadas, inúmeros estudos vêm sendo realizados a seu respeito. Uma respeitável parcela da produção acadêmica nacional the dedica estudos reiterados, sucessivos, produzindo verdadeiros tratados que hoje direcionam a cultura pátria rumo a uma teoria dos precedentes que, se ainda não é autenticamente brasileira, pelo menos vem se 
adequando às suas peculiaridades mais marcantes. ${ }^{1}$

Como um reflexo da aproximação entre os sistemas da Common Law e da Civil Law ${ }^{2}$, sentido já no século XX, postulava-se a reformulação do sistema processual que o Código de Processo Civil de 1973 representava. Com o advento da Constituição de 1988 e toda a sua carga valorativa - princípios, direitos e garantias fundamentais -, verificou-se a incapacidade de a Administração Pública cumprir tais disposições em sua totalidade.

Pode-se dizer que a partir daí a relação da sociedade civil com as instituições judiciárias se modificou de forma virtuosa. O Judiciário deixou de ser visto como um departamento técnico especializado e passou a desempenhar papel verdadeiramente político, ao lado dos dois outros poderes.

O significado disso: viu-se crescer o ajuizamento de demandas pleiteando execução de direitos fundamentais e políticas públicas. Essa ascensão institucional do Judiciário e de seus agentes, juízes e tribunais, explica-se por dois motivos determinantes:

Em primeiro lugar, pela redescoberta da cidadania e pela conscientização das pessoas em relação aos próprios direitos. Em seguida, pela circunstância de haver o texto constitucional criado novos direitos, introduzido novas ações e ampliado a legitimação ativa para tutela de interesses, mediante representação ou substituição processual. (BARROSO, 2005, p. 36)

As grandes questões de direitos fundamentais que o Poder Constituinte havia assegurado em 1988 como de competência do

\footnotetext{
${ }^{1}$ Cruz e Tucci, Teresa Arruda Alvim Wambier, Eduardo Talamini, Lênio Luiz Streck, Thomas de Bustamante, Fredie Didier Jr., Marcelo Souza, Luiz Marinoni, Daniel Mitidiero, Hermes Zaneti Jr., Lucas Macêdo, Adriana Vojvodic e muitos outros pesquisadores têm contribuído fortemente na compreensão, fortalecimento e adequada aplicação da cultura dos precedentes no sistema pátrio.

${ }^{2} \mathrm{O}$ estudo dos sistemas de Common Law e Civil Law e seus pontos em comum é essencial para a compreensão dos
}

Executivo passaram em última instância para os gabinetes dos Ministros do Supremo Tribunal Federal. Aumentaram as demandas e despontou o chamado ativismo judicial.

Além da transferência das questões políticas para a seara judicial, pesou ainda a instabilidade da jurisprudência produzida pelas próprias instituições judiciais, decorrente do uso inadequado dos precedentes na prática. Crítica forte, por exemplo, é aquela dirigida contra a produção de decisões judiciais infundamentadas ou mal fundamentadas, que se tornaram comuns na praxe forense e que motivaram a busca pelo aperfeiçoamento do sistema. Donizetti (2015, p. 3) comenta:

[...] [N]ão é incomum depararmos com juízes que, premidos pela pregação da eficiência e celeridade, lançam em suas decisões trechos de acórdãos de tribunais superiores sem justificar o porquê da aplicação da mesma tese jurídica. [...] Em nome de determinados princípios, aplicados sem qualquer explicação sobre a sua incidência ao caso concreto, o julgador se afasta completamente da lei [...].

Em absoluta contraposição à disposição constitucional da fundamentação, constante do art. 93 da Carta de 1988, essa conduta representa ainda um dos maiores obstáculos à efetivação de preceitos tais como segurança jurídica, igualdade ou isonomia, coerência, previsibilidade das decisões judiciais etc.

Da mesma forma, observa-se o manuseio equivocado das ementas e dos enunciados de súmulas, suscitados em juízo como se fossem normas gerais e abstratas desvinculadas de seus fundamentos originários; frequentemente, imagina-se que sua aplicação pode desconsiderar

precedentes judiciais. Tão forte foi o contato e influências mútuas entre os dois sistemas ao longo dos séculos, que René David (2002, p. 26) aponta os ordenamentos jurídicos da Escócia, Israel, União Sul-Africana, Quebec e Filipinas como pertencentes a uma categoria de direitos mista, que contempla tanto elementos de uma família jurídica quanto de outra. Por isso mesmo, diz ser tentadora uma nova classificação em "direitos ocidentais", complementar à tradicional classificação bipartida. 
os casos concretos e individualizáveis que lhes deram origem, o que não corresponde com a realidade desses institutos nas nações da Common Law (THEODORO JÚNIOR et al., 2015, p. 335).

Em face disso, sucessivas reformas se fizeram necessárias no decorrer da vida útil do CPC/73. Objetivos primordiais: conferir coerência e estabilidade às decisões do Judiciário, de modo a concretizar a ordem democrática imposta pelo moderno processo civil. Ao longo da construção desse novo processo, incorporou-se ao direito pátrio a figura do stare decisis; atribuiu-se ao Supremo a edição das chamadas súmulas vinculantes; implantou-se a repercussão geral nas questões submetidas a recurso extraordinário; decisões do STF em Ação Declaratória de Constitucionalidade e Ação Direta de Inconstitucionalidade passaram a ser vinculantes; bem como se facilitou o julgamento de recursos repetitivos, tudo na esteira da teoria dos precedentes judiciais.

A partir do CPC/2015, oportuniza-se de forma definitiva o diálogo entre os dois grandes sistemas de direito, tomando-se emprestado do Common Law o precedente vinculante como elemento fortalecedor da prestação jurisdicional no Brasil. Com a promulgação da Lei $n^{\circ}$ 13.105/2015, vigente desde março de 2016, antigos anseios enfim se tornam reais e surgem renovadas as expectativas quanto a maior celeridade e justiça na prestação da tutela jurisdicional.

\section{O CONSTITUCIONAL}

Previamente, faz-se necessária uma breve contextualização da jurisdição constitucional e delineamento da trajetória do próprio Estado, desde o antigo Estado Monárquico até o Estado Constitucional, perpassando pelo Estado Legislativo.
A trajetória da consolidação dos atributos do Estado culmina no Estado Constitucional, em que pesa a jurisdição constitucional e o controle de constitucionalidade. Para que se entenda a atual fase - Estado Constitucional -, faz-se necessário rememorar a trajetória histórica da figura estatal, pelo menos em seus aspectos mais marcantes e sob o enfoque da cultura Ocidental.

Cabe apenas lembrar que antes, no entanto, tal qual notadamente se repete nos manuais acadêmicos, não há propriamente uma cronologia acertada ou ordem sucessiva e regular de aparecimento dos exemplares de Estado de que trataremos. Certos tipos até mesmo coexistiram em tempo e espaço, a depender da época e do ambiente cultural e político, configurando desonestidade historiográfica transmitir tal ilusão sem antes comunicar ao leitor que tais classificações carregam consigo tão somente pretensões didáticas.

Pois bem, primeiramente, tem-se a Grécia como ponto de partida. A civilização grega, em especial Atenas, é tomada como parâmetro de organização social voltada para o bem público, administrado segundo procedimentos bem estabelecidos e que garantiam participação e representatividade inéditas até então; berço, portanto, da democracia e do constitucionalismo, retomado mais tarde pela civilização romana, cujos esteios culturais sempre foram helênicos. As cidades-estados gregas, polis, são tidas como precursoras dessa figura maior e complexa de que tratamos.

A experiência romana, por sua vez, faz-se sentir até os dias de hoje, reverberada na transmissão de valores jurídicos mesmo após a queda do Império Romano, em 476 D.C. O que à época se perdeu em matéria de tradição, todavia, foi o primado pelo constitucionalismo, em razão de circunstância e necessidade (BARROSO, 2012, p. 31).

Com a descentralização de poder decorrente do fim do Império Romano, eis que surgem 
diversos principados feudais autônomos, erigidos a partir de pequenos focos do desmembramento de Roma. O autoritarismo e o poder se entrelaçam novamente, numa tendência que acaba por culminar mais uma vez na concentração de poder e, em razão disso, no surgimento dos Estados Modernos (absolutistas), no início do Século XIV. O Império Romano cede aos feudos e, mais adiante, estes sucumbem às monarquias absolutas.

Em contraponto à teoria do direito divino dos reis e da tradição monárquica erigida a partir da alta Idade Média, eis que surgem, a partir do Século XVII, revoluções na Inglaterra, Estados Unidos da América e França, objetivando modificar o status quo até então vigente. $\mathrm{Na}$ França, o povo insurge-se contra o Ancien Régime, rompendo com o absolutismo monárquico e fortalecendo os Parlamentos e, em tese, a representatividade, na linha da máxima revolucionária Liberté, Egalité, Fraternité. A partir de então, por muito tempo, a Europa cultivou uma tradição jurídica centrada no Poder Legislativo, que acabou sendo exercido autoritariamente pelos Parlamentos.

Contra a lógica que se inverteu, isto é, contra o absolutismo legislativo, surge o movimento de fortalecimento do Judiciário, atribuindo-lhe verdadeiramente o papel de guardião dos preceitos constitucionais.

O Constitucionalismo, em sua concepção moderna, é resultado de um longo processo histórico, conforme visto, com diferentes focos de manifestação, tanto geográficos quanto temporais. A trajetória do Constitucionalismo não possui uma ordem cronológica acertada; constitui-se, sim, de fenômenos históricos e políticos que, quando não isolados, estiveram estritamente atrelados uns aos outros.

De qualquer modo, até as experiências constitucionais ditas isoladas, no sentido geográfico do termo, puderam ser aproveitadas em dado momento graças ao direito comparado e sua aceitação nas academias a partir do final do século XIX e início do século XX. Quanto a essa dialeticidade entre sistemas, é "preferível dizer que existem diversos movimentos constitucionais com corações nacionais, mas também com alguns momentos de aproximação entre si, fornecendo uma completa tessitura histórico-cultural" (CANOTILHO, 2000, p. 51).

Tais momentos de aproximação condizem bem com a história institucional do Brasil. O descobrimento tardio das Américas e a postergada colonização das terras que hoje compõem o país já apontam, por si só, as diretrizes naturais que guiaram seu processo de amadurecimento institucional. A aplicação direta das normas de Portugal no Brasil durante o alargado período em que esteve sob o jugo da metrópole lusitana e o próprio fato histórico destas terem se abeberado mais que diretamente no direito romano nos induz ao seguinte diagnóstico: a cultura jurídica pátria é tão miscigenada quanto o seu elemento étnicopopulacional. Mais ainda o é se levarmos em conta o grau de influência que exerceu e exerce em território nacional a teoria constitucional alemã. Mais tarde, no alvorecer republicano, despontaria a aproximação com o sistema angloamericano.

Isso apenas traduz a importância da Constituição enquanto uma ferramenta cuja aceitação hoje é praticamente universal, atrelada que está a expressões tais como garantias, limitação ao poder do Estado, cidadania, dignidade da pessoa humana, liberdade, dentre tantas outras que representam os anseios libertários e espirituais da sociedade moderna.

Mas, afinal, o que é Constitucionalismo senão uma técnica específica de limitação do poder com fins garantísticos; ou, ainda, um mecanismo que visa a garantir a efetividade das normas protetoras dos direitos fundamentais? Muitas são as possíveis conceituações sobre a matéria, muitas talvez unilaterais, priorizando aspectos específicos do todo, tal como o enfoque 
sociológico dado à Constituição por Ferdinand Lassale.

De modo geral, apreende-se que a autoridade impositiva da Constituição contra o poder estatal é sua característica marcante. Por sua vez, esse viés acaba por legitimar muitas das várias outras marcas conquistadas em prol do constitucionalismo moderno: o primado dos direitos e garantias fundamentais, da dignidade da pessoa humana, da igualdade etc.

Nesse sentido, Constituição se identifica ao pacto firmado pelo Estado e os sujeitos que com ele venham a se relacionar, por meio de direitos ou deveres, em que figura a imposição de limites à atuação estatal. Incompatíveis com as disposições constitucionais os atos legislativos ou administrativos, destes cabe o controle jurisdicional, ou "judicial review", bem como o controle político e o controle misto.

Apesar de o controle de constitucionalidade ser adotado por sistemas de orientação tanto romano-germânica quanto anglo-saxônica, os precedentes judiciais correspondem a uma importante figura que proporciona segurança jurídica e coesão.

\section{AS REFORMAS PROCESSUAIS}

As reformas operadas no $\mathrm{CPC} / 73$ ao longo das últimas duas décadas buscaram, em sua essência, dar efetividade aos princípios e direitos fundamentais amplamente reconhecidos pela Constituição de 1988, mas que na prática não eram prestados pelo Estado no decorrer do processo. No entanto, tantas reformas pontuais e parciais - minirreformas - acabaram por transformar o sistema processual em um todo reduzido em consistência e coerência. ${ }^{3}$

\footnotetext{
${ }^{3}$ Logo em seus parágrafos iniciais a Exposição de Motivos do $\mathrm{CPC} / 15$ atribui às muitas reformas parciais empreendidas durante a vigência do CPC/73 o enfraquecimento de sua coesão, "comprometendo sua forma sistemática" e, consequentemente, a celeridade da
}

Dinamarco (1996, p. 26) aponta que a reforma do Código de 1973 começou já durante sua vacatio legis, quando a Lei $\mathrm{n}^{\mathrm{o}} 5.925$, de $1^{\circ} \mathrm{de}$ outubro de 1973 alterou "perto de uma centena de dispositivos".

$\mathrm{O}$ autor elenca três premissas fundamentais relacionadas às minirreformas do $\mathrm{CPC} / 73$ :

[A]bertura do processo aos influxos meta-jurídicos que a ele chegam pela via do direito material; a transmigração do individual para o coletivo; e a necessidade de operacionalizar o sistema, desburocratizá-lo ou deformalizá-lo tanto quanto possivel, com vista a facilitar a obtenção de seus resultados.

No entanto, a mais importante reforma operada foi a constitucional, que salientou as tendências evolutivas da teoria dos direitos fundamentais e reforçou as "garantias do 'justo processo' (tanto civil como penal), vistas não mais exclusivamente como direitos públicos subjetivos dos litigantes, mas sobretudo como garantias para o correto exercício da jurisdição" (CINTRA et al., 2013, p. 141).

A crítica quanto à falta de coerência do Código de 1973 não the foi inteiramente exclusiva. Seu antecessor, o Código de 1939, também recebera críticas no mesmo sentido durante sua vigência, pois, não obstante possuísse uma parte geral e uma parte especial, tal como o atual, sua parte específica era "anacrônica, ora demasiadamente fiel ao velho processo lusitano, ora totalmente assistemática". A parte geral estava repleta de "ideias novas, enquanto as que tratavam dos procedimentos especiais, dos recursos e da execução se ressentiam 'de um execrável ranço medieval"” (BERMUDES apud THEODORO JÚNIOR, 2012, p. 13).

É bem verdade que foram as duas grandes guerras do século $\mathrm{XX}$ que influenciaram

prestação jurisdicional. Em seguida, justifica o novo sistema na necessidade "de um grau mais intenso de funcionalidade", onde "incluíram-se [...] outros tantos [institutos] que visam a atribuir-lhe alto grau de eficiência". 
definitivamente a mudança dos rumos do processo em escala global. $\mathrm{O}$ aspecto individualista deu lugar ao caráter social e coletivo. No Brasil, a cronologia da mudança se deu de forma mais demorada e fragmentada, principalmente em face do longo período ditatorial em que o país mergulhou entre as décadas de 1960 e 1980, o que atrasou a implementação da visão humanista e social no processo civil. As mudanças se deram de forma gradual e parcelada, resultando na inserção de diversos institutos e prerrogativas no sistema, tais como a ação civil pública, o mandado de segurança coletivo e os juizados especiais de pequenas causas. ${ }^{4}$

Muito embora estivessem ligadas à nobre determinação constitucional do acesso à justiça (art. $5^{\circ}, \mathrm{XXXV}$, da CRFB/88) e embasadas na "socialização processual", tais reformas foram provas cruciais de que as circunstâncias políticas do Brasil representavam um forte obstáculo a ser vencido. Afinal, certo é que durante seu período de vigência, o Código de 1973 viu a troca de um regime autoritário de Governo por um regime que levantou a bandeira do Estado Democrático de Direito.

A redemocratização do país, aliada à percepção e adoção da teoria dos direitos fundamentais em seu ordenamento legal, já aperfeiçoada sob a égide do Estado Constitucional, exigiu a criação de mecanismos processuais que viabilizassem os numerosos e onerosos direitos fundamentais e garantias reconhecidos a partir de então. ${ }^{5}$

\footnotetext{
${ }^{4}$ Theodoro Júnior (2012, p. 58) aponta a primeira ação de defesa de interesses difusos como sendo a ação popular, viabilizada na Lei $\mathrm{n}^{\circ} 717 / 65$; seguida pelas ações civis públicas das Leis $\mathrm{n}^{\circ}$ 7.347/1985 e 8.078/1990; seguidas, por sua vez, pela tutela dos interesses transindividuais de pessoas portadoras de deficiências na Lei $\mathrm{n}^{\circ}$ 7.853/1989, de crianças e adolescentes na Lei $\mathrm{n}^{\circ}$ 8.069/1990, de consumidores na Lei $\mathrm{n}^{\circ} 8.078 / 1990$, da probidade administrativa na Lei $\mathrm{n}^{\circ} 8.429 / 1992$ e da ordem econômica na Lei ${ }^{\circ} 8.884 / 1994$.

${ }^{5}$ Mitidiero (2013) comenta sobre a passagem do Estado Legislativo para o Estado Constitucional, em que pese ter
}

Em 1988, findado o regime militar, a constituição cidadã havia prometido mais do que podia cumprir de pronto, ou mesmo nas duas décadas que se seguiram. Consequência: abarrotamento do Judiciário com demandas muitas vezes versando sobre um mesmo bem da vida. Todas pleiteando justamente o que o Estado prometera na Constituição da República de 1988.

No mesmo sentido, Picardi e Nunes (2011, p. 100) pontuam que:

De um lado, buscou-se adaptar o sistema brasileiro aos ganhos do movimento do acesso à justiça [...], mas de outro, o Brasil se inseria, em termos institucionais, numa perspectiva neoliberal que impôs impactos no modo de se dimensionar o sistema processual, o que impediu o delineamento de uma efetiva democratização processual.

Todas as reformas na processualística brasileira nas últimas décadas, culminando na tão esperada operacionalização do $\mathrm{CPC} / 2015$, de um modo ou de outro buscaram também reafirmar a função precípua das Cortes superiores, qual seja, a uniformização da interpretação de questões constitucionais e seus tão esperados desdobramentos: prestação jurisdicional justa, isonômica, fundamentada, coerente etc.

Daí a necessidade de se reestruturar o processo civil para além de reformas pontuais, conferindo-lhe unidade e sistematização merecidas que só um novo Código poderia proporcionar. Isso contempla ainda a introdução dos precedentes com maior força no novo sistema, afinal:

havido três grandes mudanças na concepção do direito: I. Princípios e postulados ganham status de normas, junto com as regras propriamente ditas; II. Conceitos jurídicos indeterminados e as cláusulas gerais passam a compor o campo da técnica legislativa, junto com a casuística tradicional; e III. A interpretação jurídica ganha um novo significado, havendo a separação entre texto e norma. Diz o autor que "a partir dessa passagem, o processo civil passou a responder não só pela necessidade de resolver casos concretos mediante a prolação de uma decisão justa para as partes, mas também pela promoção da unidade do direito mediante a formação de precedentes." 
A estruturação de técnicas de julgamentos em larga escala (massificados) partindo-se de suposta homogeneidade de casos (idênticos), devido às contingências de um sistema com inúmeros problemas operacionais de aplicação e a busca de uma Justiça de números, não pode negligenciar a aplicação coerente dos direitos fundamentais dos cidadãos sob argumentos econômicos e funcionais. (THEODORO JÚNIOR et al., 2015, p. 238)

Essa tendência já vinha se consolidando desde a Emenda Constitucional n ${ }^{\circ} 45 / 2004$, com a introdução da Súmula Vinculante. Mas antes mesmo, quando da edição da Emenda Constitucional $n^{0}$ 03/1993, a tendência de aproximação do sistema jurídico brasileiro ao anglo-americano já era nítida.

A EC $n^{\circ} 03$, por exemplo, ao introduzir o $\S$ $2^{\circ}$ ao art. 102 da CRFB/1988, concedeu eficácia erga omnes e eficácia vinculante às "decisões definitivas de mérito, proferidas pelo Supremo Tribunal Federal, nas ações diretas de inconstitucionalidade e nas ações declaratórias de constitucionalidade", podendo ser considerada marco normativo da aplicação dos precedentes judiciais no Brasil (DONIZETTI, 2015, p. 7).

O Brasil é híbrido por excelência, não só em sua base étnico-cultural, mas consequentemente também em sua constituição jurídica. Exemplo popular disso é o controle de constitucionalidade pátrio, tanto de origem americana (controle difuso) quanto de inspiração continental europeia (controle concentrado). Outra marca é a produção legislativa robusta, que convive com a valorização cada vez mais forte das súmulas de tribunais, súmulas vinculantes do STF, julgamentos modelo de causas repetitivas etc.

Evidentemente, não seria apenas essa ou outras iniciativas similares responsáveis, por si só, pela conclusão de que o sistema brasileiro está cada vez mais próximo da integridade prática típica de uma nação da Common Law. Longe

\footnotetext{
${ }^{6}$ Tradução livre do respectivo verbete constante do célebre Black's Law Dictionary: “An adjudged case or decision of a court of justice, considered as furnishing an example or
}

disso. Afinal, "nada que o novo CPC traz a respeito do assunto [...] autoriza afirmações genéricas que vêm se tornando comuns, no sentido de que o direito brasileiro migra em direção ao Common Law ou algo do gênero". (BUENO, 2015, p. 567)

Muito embora o Brasil importe institutos anglo-americanos por natureza e origem, isso não indica uma transição, mas sim uma saudável comunicabilidade acadêmica decorrente do estudo do Direito Comparado e uma capacidade de adaptação mais que natural da hibridez jurídica brasileira.

\section{OS PRECEDENTES NO NOVO CÓDIGO DE PROCESSO CIVIL}

Precedente parece ser uma expressão de fácil compreensão. $\mathrm{E}$ de fato o é. Enquanto vocábulo ordinário, a palavra remete a algo prévio, anterior, que precede algo no tempo. No direito não é diferente.

Precedente é uma demanda já ajuizada e resolvida ou uma decisão judicial já proferida que ostenta ora valor persuasivo ora autoridade impositiva para eventuais casos que venham a ser suscitados em juizo, sejam idênticos ou meramente semelhantes. ${ }^{6}$ (BLACK, 1968, p. 1340)

Para Frederik Schauer (2011, p. 3), há dois tipos de precedentes: os de vinculação vertical e os de vinculação horizontal. Os verticais dizem respeito à "cadeia de comando", hierarquia, em que as cortes inferiores devem seguir obrigatoriamente as decisões das cortes superiores; os horizontais, por outro lado, implicam uniformidade jurisprudencial quanto a uma mesma corte considerada individualmente, que deve seguir uma linha decisória sem contradições. Estes últimos é que se identificam

authority for an identical or similar case afterwards arising or a similar question of law." 
com o que popularmente se chama de stare decisis.

Há, ainda, outras classificações, tais como precedentes persuasivos, precedentes relativamente obrigatórios e precedentes absolutamente obrigatórios. Dessas classificações importa abordar tão somente os precedentes persuasivos ou obrigatórios, numa síntese que não parece prejudicar a tratativa da matéria. $\mathrm{O}$ contraponto entre esses dois tipos de precedentes está na sua autoridade e, também, na sua vinculação com o stare decisis.

Uma vez obrigatórios, há que se falar na máxima do stare decisis et non quieta movere, isto é, respeitar as decisões postas e não alterar o que está estabelecido. ${ }^{7}$ (BLACK, 1968, p. 1578)

No que diz respeito à cultura dos precedentes judiciais, o NCPC, ao dispor em seu art. 926 que "os tribunais devem uniformizar sua jurisprudência e mantê-la estável, íntegra e coerente", consagra o primado dos precedentes no sistema que se inaugura. Mas isso não exime o novo código de críticas, dentre as quais a que contesta o seu alto teor prescritivo e a falta de mecanismos verdadeiramente processuais e pormenorizados que garantam a efetividade do cumprimento do dever de uniformização jurisprudencial (SALLES, 2015, p. 78).

Todavia, isso deve ser resolvido por nova legislação processual extravagante, que deverá procedimentalizar tantas outras prescrições gerais no sentido de respeito aos precedentes.

$\mathrm{Na}$ esteira da prevalência dos pronunciamentos judiciais carregados de vinculatividade, o CPC/2015 não só confirma eficácia erga omnes às decisões em sede de controle de constitucionalidade, como também amplia as hipóteses de aplicabilidade dos precedentes obrigatórios, dando seguimento à tendência iniciada em meados do século passado.
Cassio Scarpinella Bueno (2015, p. 568) anota que, apesar de não estar explícito no texto, o novo CPC

\begin{abstract}
[..] [N]ão emprega a palavra "vinculante" no sentido que aqui interessa. Ela parece ser insinuada com o uso de afirmativos imperativos toda vez que a temática dos "precedentes" e dos "julgamentos repetitivos" vem à tona, prevê-se, até mesmo - e expressamente - o uso da reclamação para afirmar e reafirmar a "observância" dos precedentes (art. 988, IV), mas, do ponto de vista textual, aquela palavra é evitada. Ela só é empregada pelo novo CPC para indicar as Súmulas Vinculantes do STF - mas, para estas, há expressa previsão constitucional - e, no § $3^{\circ}$ do art. 947, a propósito do Incidente de Assunção de Competência, lê-se que o acórdão proferido vinculará rodos os juízes é órgãos fracionários, exceto de houver revisão de tese.
\end{abstract}

No Código de 2015, o termo "precedente" é utilizado no artigo 926, $\S 2^{\circ}$, em sua acepção tradicional, comum, qual seja, simples decisões judiciais que poderão ser usadas, a depender das circunstâncias futuras, como parâmetros de julgamentos de novas demandas, quando houver aspectos identificadores suficientes que justifiquem o embasamento jurisprudencial.

Nos demais artigos, a expressão parece fazer referência principalmente - se não tãosomente - aos precedentes obrigatórios, distintos daqueles acima comentados em razão do grau de hierarquia e respeitabilidade que ultrapassa a fronteira do processo em análise, estendendo-se a outras partes de outras demandas sub judice.

Outra conquista do Código de 2015 parece pretender superar aquela crítica exposta bem mais acima, quanto à prática equivocada de uso e colação de julgados desconexos do caso corrente como se precedentes fossem. Equívoco comum na prática forense. $\mathrm{O} \S 2^{\circ}$ do art. 926 dispõe que "ao editar enunciados de súmulas os tribunais devem ater-se às circunstâncias fáticas dos precedentes

\footnotetext{
${ }^{7}$ Tradução livre do respectivo verbete constante do célebre Black's Law Dictionary: "To adhere to precedents, and not to unsettle things which are established."
} 
que motivaram sua criação". Para Humberto Theodoro Júnior (2015, p. 248):

O equívoco não se resume ao uso dos julgados como se lei fossem, com a utilização de uma "metodologia" tradicional que os presume (ementas e enunciados de súmula) como enunciados normativos abstratos (dos casos julgados), mas na sua construção desde o início como esgotamentos interpretativos quando produzidos por técnicas de causa-piloto (como as da repercussão geral do recurso extraordinário no STF ou do recurso especial do STJ) que induzem o erro de que, uma vez sendo proferida a decisão por estes órgãos de cúpula do Judiciário pátrio, teríamos chegado a um padrão decisório preciso, abrangente e que poderia ser aplicado mecanicamente mediante uma simples subsunção.

Isto significa enrijecer a aplicação dos precedentes, distintos de casos julgados quaisquer, e identificáveis entre si por meio de técnicas próprias de cruzamentos fáticos. Se antes se postulava perante o juízo utilizando-se como fundamento ementa de um julgado sem considerar sua base fática ou ainda súmulas de tribunais, sem adentrar no mérito dos casos que as tinham originado, agora isso não mais pode acontecer. Não mais devem ser confundidas ementas ou súmulas com normas genéricas e abstratas tais quais as legislativas.

Interessante é o modo como a aplicação dos precedentes pelos tribunais está ainda atrelada à fundamentação das decisões judiciais. O art. 489, que em seu caput elenca os elementos essenciais da sentença, define em seu $\S 1^{\circ}$ as balizas para a correta fundamentação das decisões judiciais e não eventuais simulações de fundamentação.

O dispositivo aponta que não se considera fundamentada a decisão judicial de qualquer tipo nas seguintes hipóteses: (inciso I) quando se limitar a indicar, reproduzir ou parafrasear ato normativo, sem explicar sua relação com a causa ou a questão decidida; (inciso II) quando empregar "conceitos jurídicos" indeterminados, sem explicar sua incidência no caso; (inciso III) invocar motivos que prestariam a justificar outras decisões; (inciso IV) não enfrentar todos os argumentos deduzidos no processo que sejam capazes de infirmar a conclusão adotada pelo julgador; (inciso V) quando se limitar a invocar precedente ou enunciado de súmula, sem identificar seus elementos e demonstrar seu ajuste ao caso; e, por fim, (inciso VI) quando não seguir enunciado de súmula, jurisprudência ou precedente invocado pela parte, sem fazer uso das técnicas da distinção do caso ou da superação do entendimento.

A fundamentação dos atos decisórios, verdadeiro instrumento que promove a publicidade e a veiculação da psique jurídica do juiz, isto é, sua motivação e sua imparcialidade. Num quadro maior ainda, é "através da motivação que se avalia o exercício da função jurisdicional" (FERNANDES, 1999, p. 14).

É a fundamentação que viabiliza que seja fiscalizada a conduta ética do aplicador do direito, bem como seja posta à prova sua capacidade intelectual para o exercício das funções judicantes.

\section{OS PRECEDENTES E O SUPREMO TRIBUNAL FEDERAL: ANTES E DEPOIS DO CPC/2015}

$\mathrm{Na}$ estrutura do Judiciário brasileiro, o Supremo Tribunal Federal desponta como tendo por funções constitucionalmente estabelecidas julgar determinadas causas originárias (art. 102, inc. I c/c art. 103, $\left.\S 2^{\circ}, \mathrm{CRFB} / 88\right)$, bem como julgar recursos ordinários (art. 102, inc. II, CRFB/88) e extraordinários (art. 102, inciso III, $\mathrm{CRFB} / 88)$.

Originariamente, o STF possui amplas atribuições, dentre as quais se destacam a competência para julgar a ação direta de inconstitucionalidade, a ação declaratória de constitucionalidade, a arguição de descumprimento de preceito fundamental, a ação 
direta de inconstitucionalidade por omissão e o mandado de injunção. ${ }^{8}$

De modo extraordinário, o STF atua como última instância de todas as Justiças, comuns ou especiais, quanto ao julgamento dos recursos extraordinários, porém limitando-se a analisar questões de direito que guardem relação ao respeito da ordem constitucional.

Tanto as causas originárias acima destacadas quanto o julgamento de recurso extraordinário compõem o "núcleo do sistema de controle de constitucionalidade e legitimidade de leis ou atos normativos, bem como das omissões inconstitucionais" (BRANCO; MENDES, 2015, p. 984).

Estritamente no caso do recurso extraordinário, por se sobrepor às diversas Justiças, ainda que não lhes integre ou pertença em questão de estrutura, o STF funciona como órgão de superposição (CINTRA et al., 2013, p. 207).

Interessante é o estudo feito por Daniel Mitidiero (2013, p. 12, grifo do autor) no que diz respeito à efetiva atuação do STF e também do STJ enquanto cortes que ocupam o vértice da organização judiciária. Ao afirmar que ambas, ao contrário do que seria desejável, pendem em verdade mais para o modelo de Cortes Superiores do que para o de Cortes Supremas, estabelece como elemento de distinção o valor dado ao precedente como meio orientador da sociedade civil e da comunidade jurídica a respeito do significado que deve ser atribuído aos enunciados legislativos:

A interpretação é o fim das cortes de vértice [...] e a formação do precedente tem um papel central, de modo que a violação à interpretação ofertada pela corte de vértice pelos juízes que compõem a própria corte e por aqueles que se encontram nas instâncias ordinárias é vista como uma grave falta institucional que não pode ser tolerada dentro do sistema jurídico.
A essência da Suprema Corte brasileira é marcada pela eficiência na aplicação das normas constitucionais e na guarda dos direitos fundamentais. A história nos mostra que essa função parece estar longe de ter seu alcance e significado reduzidos, à medida que crise tornase uma palavra cada vez mais frequente no vocabulário do povo brasileiro. Crise econômica. Crise política. Crise de representatividade. Crise do presidencialismo etc. Isso tudo torna cada vez mais evidente a necessidade crescente de se invocar o Judiciário a solucionar impasses entre os dois outros poderes.

Nesse sentido, Alexandre de Moraes (2000, p. 59) diz:

\begin{abstract}
Nesse panorama de crise do sistema representativo e aumento dos reclamos sociais por outros canais de pressão ao governo, que não mais exclusivamente por meio dos representantes eleitos no Parlamento, torna-se cada vez mais necessária a adoção de dois mecanismos complementares, de fortalecimento da democracia: reforma política do Estado e atuação do Tribunal Constitucional como árbitro da sociedade.
\end{abstract}

Como já visto, antes do CPC/15, as ações de controle direto de constitucionalidade do STF já possuíam eficácia erga omnes, possuindo, portanto, vinculatividade estrita, sendo verdadeiros precedentes obrigatórios. Agora, com a vigência da nova codificação, ganham vinculatividade universal as decisões em sede de recursos especiais e de recursos extraordinários repetitivos (art. 1029, $\S 4^{\circ}$ ), as decisões proferidas nos incidentes de resolução de demandas repetitivas (art. 985, $\S 1^{\circ}$ ) e incidentes de assunção de competência (art. 947, § $3^{\circ}$ ), bem como se prescreve nos artigos 926 e 927 o dever uniformização, estabilização, coerência, integridade e obediência da jurisprudência nacional.

102, inciso I, alínea q, do art. 102, todos constantes da CRFB/88.

\footnotetext{
${ }^{8}$ Respectivamente, ADI e ADC - inciso I, alínea a, do art.
} 102; ADPF - $\S 1^{\circ}$ do art. 102; ADO - art. 103; e MI - art. 
Consequentemente, os valores que hoje são inerentes ao que se chama de Neoconstitucionalismo, tais como igualdade, dignidade da pessoa humana, segurança jurídica, coerência e previsibilidade das decisões recebem uma importante carga de efetividade no novo sistema.

O sistema processual de 1973 já tratava de precedentes, isso não se questiona. $\mathrm{O}$ que o novo código inaugura é a clareza legislativa, isto é, a menção literal ao instituto e à obrigatoriedade de sua obediência, o que na tradição brasileira pesa muito mais do que a espontânea assimilação por meio de costumes e prática.

Levando-se em conta o fato de não serem, a princípio, obrigatórios os precedentes no Brasil (SOUZA, 2006, p. 176) ${ }^{9}$, com exceção daquelas decisões que a lei gradualmente passou a reconhecer como vinculantes ou de eficácia erga omnes, são os precedentes obrigatórios que ganham força na nova sistemática processual, à medida que se reforça o valor das decisões das cortes superiores e promove-se a uniformização de jurisprudência em todos os níveis da Justiça.

Vale ressaltar que nos países da Common Law o respeito à autoridade das Cortes superiores como intérpretes da constituição e promotoras da uniformização jurisprudencial encontra justificativa em séculos de costumes consolidados, diferentemente do Brasil, onde a teoria dos precedentes se fortalece por imposição legal.
6 DUAS NOVIDADES DO CPC/2015: O INCIDENTE DE RESOLUÇÃO DE DEMANDAS REPETITIVAS (IRDR) E O INCIDENTE DE ASSUNÇÃO DE
COMPETÊNCIA (IAC)

Com previsão expressa nos arts. 976 a 987 do CPC de 2015, o incidente de resolução de demandas repetitivas, ou IRDR, como é chamado, é instituto inovador da sistemática processual presente no Novo Código de Processo Civil, e consagra o sistema de precedentes aludido no ordenamento jurídico brasileiro.

O objetivo do IRDR é, de forma direta e simples, a uniformização da jurisprudência decorrente de demandas repetitivas, considerando-se como tais aquelas que possuem o objeto e a causa de pedir idênticos, impedindo, assim, a insegurança jurídica e garantindo a isonomia.

Vale ressaltar, neste ponto, que não se trata de hipótese de conexão, vez que esta necessita do mesmo objeto ou mesma causa de pedir para que seja perfectibilizada. O objeto ou a causa de pedir dos processos passíveis de IRDR devem ser, em verdade, iguais, e não os mesmos. Alexandre Freitas Câmara (2015, p. 71) exemplifica:

\begin{abstract}
Se dois acionistas de uma companhia ajuízam demandas individuais e autônomas para postular a anulação de uma certa assembleia geral, essas duas demandas terão o mesmo objeto (já que em ambas se busca a invalidação do mesmo ato). Se um condomínio edilício ajuíza, em face de dois diferentes condôminos, demandas de cobrança de quotas condominiais atrasadas, essas demandas não têm o mesmo objeto (já que em cada uma delas se busca o pagamento de uma dívida diferente), ainda que tenham elas objetos iguais.
\end{abstract}

\footnotetext{
${ }^{9}$ Entenda-se aqui a diferença do uso dos precedentes no Brasil e em países de Common Law: no sistema angloamericano um juiz deve seguir a mesma linha decisória de um caso previamente julgado se os seus elementos justificadores coincidirem, mesmo que não concorde com a solução prática da lide; se dela discordar, para julgar de modo diferente, deve comprovar distinção entre o caso
}

corrente e o precedente. Além disso, o respeito aos precedentes se dá de forma natural e costumeira. No Brasil, os precedentes, a princípio, são meramente persuasivos, podem ou não influenciar a decisão de um juiz, havendo observância obrigatória apenas em casos específicos e previstos em lei. 
Esclarecida essa diferença, importante destacar ainda outras características do instituto. Quanto aos requisitos de admissibilidade do IRDR, tais condições estão previstas no art. 976 do $\mathrm{CPC} / 2015$. Assim, para que o referido incidente seja primeiramente admitido, será necessária a comprovada repetição de processos os quais contenham controvérsia sobre a mesma questão, que deverá ser unicamente de direito. Além disso, será imprescindível o risco de ofensa à isonomia e à segurança jurídica.

Coube ao $\S 4^{\circ}$ do art. 976 estabelecer condição negativa à instauração do IRDR, afirmando não ser cabível o incidente quando um dos tribunais superiores, no âmbito de sua competência, já tiver afetado recurso para a definição de tese sobre questão de direito material ou processual repetitiva.

No entanto, além dos requisitos previstos na legislação processual, há ainda um quarto requisito, objeto do Enunciado 344 do Fórum Permanente de Processualistas Civis (FPPC), segundo o qual é necessária a existência de ao menos um processo pendente perante o tribunal respectivo para que seja instaurado o incidente.

No que diz respeito aos seus legitimados, o IRDR poderá ser instaurado pelo juiz ou relator $e x$ officio, pelas partes, ou ainda pelo Ministério Público e Defensoria Pública, sendo estes três últimos através de petição.

A instauração do IRDR deverá ser realizada perante os tribunais de segunda instância, sendo estes tribunais de justiça e tribunais regionais (incluem-se os tribunais regionais federais e tribunal regional do trabalho). No que diz respeito aos tribunais superiores, embora não haja previsão expressa desta possibilidade, Didier (2016, p. 625) esclarece que não há qualquer previsão do contrário, não havendo no CPC/2015, portanto, restrições ao cabimento do IRDR.

$O$ incidente de resolução de demandas repetitivas, quando solucionado, terá ainda eficácia vinculante, funcionando como verdadeiro precedente jurisprudencial. Importante ressaltar, da mesma forma, que o julgamento dos futuros incidentes em comento no ordenamento jurídico brasileiro proporcionará maior celeridade processual, vez que o entendimento pacífico deverá ser respeitado tanto por juízes de primeiro grau quanto em grau recursal. Tais benefícios do incidente configuram explícita evolução do sistema processual de precedentes $\mathrm{e}$ as expectativas das melhorias na prática tendem a crescer ainda mais.

Importante ressaltar ainda o papel do STF na garantia da aplicação deste incidente nas demandas repetitivas. Em verdade, tanto o Supremo Tribunal Federal quanto o Superior Tribunal de Justiça possuem atuação mais significativa no que diz respeito à hipótese de suspensão de todos os processos individuais ou coletivos em curso no território nacional que versem sobre questão objeto do incidente já instaurado.

A inclusão da hipótese de suspensão dos processos no âmbito nacional no art. $982, \S 3^{\circ}$ do CPC/2015 é oriunda da possibilidade da ocorrência de múltiplos incidentes de resolução de demandas repetitivas sobre a mesma questão de direito no território brasileiro. Isto ocorre porque, quando admitido, o IRDR ocasiona a suspensão dos processos que tratam da mesma questão de direito existentes apenas no território estadual no qual atua o respectivo tribunal. Seria possível, assim, a instauração simultânea desses incidentes sobre questão idêntica nos vinte e sete tribunais de justiça existentes na federação.

Por esta razão, a suspensão nacional determinada pelo STF ou STJ é possibilidade inerente à garantia da isonomia e da segurança jurídica. Entende-se que o IRDR é, portanto, instituto essencial ao sistema de precedentes aludido no $\mathrm{CPC} / 2015$, tornando-se imprescindível na padronização das decisões jurídicas a respeito da mesma questão de direito e na consequente uniformização de jurisprudência. 
Já quanto ao Incidente de Assunção de Competência (IAC) desde a vigência do $\mathrm{CPC} / 2015$ o instituto vem sendo erroneamente confundido com o incidente de resolução de demandas repetitivas, embora sejam incidentes com aplicabilidades completamente divergentes.

Inicialmente, é importante ter em mente que, para a aplicação do IAC em determinado processo, o mesmo não poderá ser exemplo de demanda repetitiva. Note-se que não se trata de caso de dispensabilidade, mas sim de exigibilidade. A ausência de múltiplos processos sobre a questão objeto do incidente de assunção de competência é requisito obrigatório para a sua instauração, diferenciando-o substancialmente do Incidente de Resolução de Demandas Repetitivas.

Tal entendimento foi objeto do Enunciado 334 do Fórum Permanente de Processualistas Civis: "Por força da expressão 'sem repetição em múltiplos processos', não cabe o incidente de assunção de competência quando couber julgamento de casos repetitivos".

O Incidente de Assunção de Competência encontra previsão no art. 947 do CPC/2015 e foi criado com o objetivo de auxiliar na formação dos precedentes com eficácia vinculante. Cabível no julgamento de recurso, remessa necessária ou processo de competência originária, o IAC possui como requisito de admissibilidade que $o$ julgamento envolva relevante questão de direito, com grande repercussão geral.

$\mathrm{O} \S 4^{\circ}$ do art. 947 do CPC/2015 reitera ainda que o IAC será instaurado quando ocorrer relevante questão de direito a respeito da qual seja conveniente a prevenção ou a composição de divergências entre câmaras ou turmas do tribunal.

O IAC poderá ser proposto pelo relator ex officio, a requerimento da parte, do Ministério Público ou da Defensoria Pública, quando será realizada votação no órgão colegiado para a sua admissibilidade. Em caso positivo, o incidente será julgado peço órgão colegiado que o regimento interno do tribunal indicar.
Sabendo que o incidente de assunção de competência contribui para a efetivação dos precedentes, é válido destacar observação pertinente de Didier (2016, p. 385):

\begin{abstract}
A obediência aos precedentes e a uniformização da jurisprudência prestam-se a concretizar, ainda, a segurança jurídica, garantindo previsibilidade e evitando a existência de decisões divergentes para situações semelhantes, sendo certo que decisões divergentes não atingem a finalidade de aplacar os conflitos de que se originaram as demandas. Casos iguais devem ter, necessariamente, decisões iguais, sob pena de se instaurar um estado de incerteza. $\mathrm{O}$ respeito aos precedentes assegura a segurança jurídica, conferindo credibilidade ao Poder judiciário e permitindo que os jurisdicionados pautem suas condutas levando em conta as orientações jurisprudenciais já firmadas. Em outras palavras, o respeito aos precedentes estratifica a confiança legítima: os jurisdicionados passam a confiar nas decisões proferidas pelo judiciário, acreditando que os casos similares terão o mesmo tratamento e as soluções serão idênticas para situações iguais.
\end{abstract}

O incidente de assunção de competência, portanto, ainda que seja procedimento diverso do incidente de resolução de demandas repetitivas, possui como característica em comum a busca pela uniformização da jurisprudência, atuando como instrumento hábil para a concretização efetiva e prática da padronização de decisões judiciais.

\section{CONCLUSÃO}

O Código de Processo Civil de 2015, cuja vigência se iniciou a partir de 18 de março de 2016, traz consigo o primado dos precedentes judiciais, que muitos autores identificam como "precedentes à brasileira", por se tentar reforçar a vinculação de certas decisões judiciais tal qual nos sistemas da Common Law.

A prática, contudo, exigirá ainda amplas discussões a respeito do assunto, uma vez que a realidade brasileira da aplicação do direito jurisprudencial é bastante distinta da realidade da Common Law. Não obstante o esforço de mais de 
cinco décadas, iniciado com a edição de Súmulas pelo STF em 1963, a tratativa prática dos precedentes com a finalidade de uniformizar o direito se mostrou superficial.

A utilização de enunciados de súmulas e ementas de acórdãos de forma abstrata e genérica, como se lei fossem, denuncia o alto grau de preferência ao direito legislado em detrimento do uso de técnicas de distinção e superação dos fundamentos determinantes da decisão tomada como paradigma, isto é, as rationes decidendi.

Parece demonstração mais que suficiente de que se está dando espaço e voz à doutrina para que desenvolva, à luz da academia, uma nova e verdadeira teoria dos precedentes judiciais brasileiros; o que, todavia, não faria sentido se não se fizesse acompanhar de uma complexa reforma cultural da sociedade e das instituições que com ela dialogam.

Afinal, a lógica dos precedentes no âmbito do STF enquanto Corte Superior, bem como dos tribunais superiores em geral, coaduna-se com valores já amplamente repisados ao longo deste trabalho: segurança jurídica, isonomia, justiça, celeridade, dignidade da pessoa humana, coerência, uniformidade e previsibilidade da tutela jurisdicional.

Aqui, bem se encaixa a ideia contida no trecho do romance $O$ Leitor, do jurista alemão Bernhard Schlink, citado em epígrafe no início deste trabalho, de que a História do Direito é marcada por avanços e recuos, repleta de chegadas e partidas, ocasionalmente abalada por fracassos e gloriosa em suas conquistas.

Nesse sentido, a Lei $\mathrm{n}^{\mathrm{o}} 13.105 / 2015$ representa um verdadeiro avanço na cultura jurídico-administrativa brasileira, à medida que revigora a busca pela efetividade da prestação da tutela jurisdicional, mediante a cooperação entre os Poderes Executivo, Legislativo e Judiciário.

Essa verdadeira Odisseia - a busca pela efetividade do direito - jamais será em vão enquanto cada cidadão e agente público, todos eles células do Estado Constitucional, persistir no seu encalço.

\section{REFERÊNCIAS}

BARROSO, Luís Roberto. Curso de direito constitucional contemporâneo: os conceitos fundamentais e a construção do novo modelo. 3. ed. São Paulo: Saraiva, 2012.

Neoconstitucionalismo e constitucionalização do direito: o triunfo tardio do direito constitucional no Brasil. Revista de Direito Administrativo, Rio de Janeiro, v. 240, p. 1-42, abr./jun. 2005. Disponível em: <http://bibliotecadigital.fgv.br/ojs/index.php/rda/article/view/43618/44695>. Acesso em: 10 abr. 2016.

BASÍLIO, Ana Tereza; DE MELO, Daniela Muniz Bezerra. IRDR potencializa resultado de julgamentos de processos repetitivos. Revista Consultor Jurídico, São Paulo, 2 out. 2015. Disponível em: $\quad<$ http://www.conjur.com.br/2015-out-02/irdr-potencializa-resultado-julgamentos-processosrepetitivos $>$. Acesso em: 25 jun. 2016.

BERMUDES, Sergio. Introdução ao direito processual civil. 1. ed. Rio de Janeiro: Liber Juris, 1973.

BLACK, Henry C. Black's Law Dictionary. 4. ed. Saint Paul: West Publishing, 1968.

BRASIL. Constituição Federal (1988). Constituição da República Federativa do Brasil. Brasília, DF: Senado Federal, 1988. 
Lei $n^{\circ}$ 13.105, de 16 de março de 2015. Código de Processo Civil. Disponível em: <http://www.planalto.gov.br/ccivil_03/_Ato2015-2018/2016/Lei/L13300.htm>. Acesso em: 28 jul. 2016.

BUENO, Cassio Scarpinella. Novo Código de Processo Civil anotado. São Paulo: Saraiva, 2015.

CÂMARA, Alexandre Freitas. O Novo Processo Civil Brasileiro. 1. ed. São Paulo: Atlas, 2015.

CANOTILHO, J. J. Gomes. Direito constitucional e teoria da constituição. 4. ed. Coimbra: Almedina, 2000.

CINTRA, Antônio Carlos de Araújo; GRINOVER, Ada Pellegrini; DINAMARCO, Cândido Rangel. Teoria Geral do Processo. 29. ed. São Paulo: Malheiros, 2013.

DAVID, René. Os grandes sistemas do direito contemporâneo. Trad. Hermínio A. Carvalho. 4. ed. São Paulo: Martins Fontes, 2002.

DIDIER Jr., Fredie; DA CUNHA, Leonardo Carneiro. Curso de Direito Processual Civil: meios de impugnação às decisões judiciais e processo nos tribunais, v. 3. 13. ed. Salvador: Juspodivm, 2016.

DINAMARCO, Cândido Rangel. A reforma do código de processo. 3. ed. São Paulo: Malheiros, 1996.

DONIZETTI, Elpídio. Curso didático de direito processual civil. 19. ed. São Paulo: Atlas, 2016.

. A força dos precedentes no novo Código de Processo Civil. Revista Unifacs, 2015. Disponível em: <http://www.revistas.unifacs.br/index.php/redu/article/viewFile/3446/2472>. Acesso em: 22 fev. 2016.

FERNANDES, Antonio Scarance. Processo Penal Constitucional. São Paulo: Revista dos Tribunais, 1999.

MENDES, Gilmar Ferreira; BRANCO, Paulo Gustavo Gonet. Curso de Direito Constitucional. 10. ed. São Paulo: Saraiva, 2015.

MITIDIERO, Daniel. Cortes Superiores e Cortes Supremas: do controle à interpretação, da jurisprudência ao precedente. São Paulo: Revista dos Tribunais, 2013.

NUNES, Dierle; PICARDI, Nikolas. O Código de Processo Civil Brasileiro: origem, formação e projeto de reforma. Revista de Informação Legislativa, Brasília, ano 48, n. 190, abr./jun. 2011. Disponível

em:

$<$ http://www2.senado.leg.br/bdsf/bitstream/handle/id/242945/000939985.pdf?sequence=3>. Acesso em: 10 abr. 2016.

. É preciso repensar o modo como os tribunais vêm atuando. Revista Consultor Jurídico, São Paulo, 11 jun. 2014. Disponível em: <http://www.conjur.com.br/2014-jun-11/dierle-nunes-precisorepensar-modo-tribunais-atuam>. Acesso em: 23 mai. 2016.

SALLES, Carlos Alberto. Precedentes e jurisprudência no novo CPC. In: BONATO, Giovanni (Ed.). Novo Código de Processo Civil: questões controvertidas. São Paulo: Atlas, 2015. 
SCHAUER, Frederick. Precedent. SSRN, Rochester, NY, 16 May 2011. Disponível em: $<$ http://dx.doi.org/10.2139/ssrn.1836384>. Acesso em 08 de abril de 2016.

SOUZA, Marcelo Alves Dias de. Do precedente judicial à súmula vinculante. Curitiba: Juruá, 2006.

THEODORO JÚNIOR, Humberto. Teoria Geral do direito processual civil e processo de conhecimento. Rio de Janeiro: Forense, 2012.

; NUNES, Dierle; BAHIA, Alexandre Melo Franco; PEDRON, Flávio Quinaud. Novo CPC: fundamentos e sistematização. 2. ed. Rio de Janeiro: Forense, 2015.

Recebido em: 24/09/2016

Aceito em: 28/12/2016 
